\title{
Current Challenges in Hematology: Awareness, Prevention, Equity
}

\author{
Dominic Kaye ${ }^{1 * t}$ and Alessandro Isidori ${ }^{2 * t}$ \\ ${ }^{1}$ Frontiers in Oncology, Frontiers Media SA, Lausanne, Switzerland, ${ }^{2}$ Hematology and Stem Cell Transplantation, AORMN \\ Hospital, Pesaro, Italy
}

Keywords: hematologic malignancies, health equity, cancer care, access to cancer services, cancer awareness, cancer prevention

\section{INTRODUCTION}

Hematologic malignancies make up approximately $10 \%$ of all cancer types in the USA, and the management of patients suffering from hematologic malignancies has dramatically changed over the last 20 years (1). Death rates have reduced across the various malignancy types, and rapidly fatal

OPEN ACCESS

Edited by:

Varsha Gandhi,

University of Texas MD Anderson Cancer Center, United States

Reviewed by:

Giuseppe Giaccone,

Cornell University, United States

${ }^{*}$ Correspondence:

Dominic Kaye

pdakaye@gmail.com

Alessandro Isidori

aisidori@gmail.com

tThese authors have contributed equally to this work

Specialty section:

This article was submitted to Hematologic Malignancies,

a section of the journal

Frontiers in Oncology

Received: 13 January 2021

Accepted: 06 April 2021

Published: 27 April 2021

Citation:

Kaye D and Isidori A (2021) Current Challenges in Hematology: Awareness, Prevention, Equity.

Front. Oncol. 11:653020. doi: 10.3389/fonc.2021.653020 diseases, such as chronic myeloid leukemia, have become curable thanks to therapies like Imatinib Mesylate, occasionally termed an oral 'magic bullet' (1-3). Pathologies ignored by most, with little or no therapeutic possibilities, based only on conventional chemotherapy, have captured the spotlight: chronic lymphocytic leukemia, C(LL)inderella, very recently became a star, with numerous ongoing clinical trials and several novel agents approved $(4,5)$. Another case in point is the outcome of multiple myeloma (MM), the second most frequent hematologic malignancy type after non-Hodgkin lymphoma (NHL), has significantly improved in recent years, again thanks to the introduction of novel therapeutic agents (6). A better understanding of disease heterogeneity, together with the discovery of novel targeted agents to be used in combination with chemotherapy, has also significantly improved the prognosis of acute myeloid leukemia (AML), the big bad wolf for any hematologist (7). Lastly, the advent of Chimeric Antigen Receptor T (CAR-T) Cells has brought upon similar advances and positive outcomes in a number of patients, and as of February 2021, there are four CAR-T Cell therapies approved by the FDA for use in patients, and numerous additional ongoing clinical trials. CAR-T Cells are a novel personalized cancer therapy which acts directly on the immune system of patients, making it able to recognize and destroy tumor cells, and has granted the opportunity to treat advanced forms of hematological malignancies in resistant and relapsed patients, and to survive $(8,9)$.

What challenges does a hematologist face in 2021, if any? As a matter of fact, all that glitters is not gold. This year's World Cancer Day is focused on awareness, prevention and equity. When thinking about it, it is not strange that these are the themes that were selected this year. Let's explore why.

\section{AWARENESS}

Wikipedia defines awareness as "the state of being conscious of something. More specifically, is the ability to directly know and perceive, to feel, or to be cognizant of events" (10). When applied to patients, awareness is the state of being conscious of the disease and its symptoms. It is therefore necessary to ensure that screening, early detection, and education surrounding the disease is further increased. A lack of awareness can be attributed to a number of reasons. An inability to access 
information, and more importantly accurate information, is one key reason for a lack of awareness. This, unfortunately, can often be made harder through the presence of stigma associated to cancer, which can prevent individuals from taking preventative action, or even receiving medical check-ups, out of fear. A case in point is, according to an UICC report, only $36 \%$ of people surveyed across Africa view cancer as a major health issue, and $25 \%$ believe that cancer has no cure (11). If people are aware of a disease and its symptoms, they are more likely to act in order to prevent it from happening to them, through means such as participating in screening programs, regularly checking their health status, and visiting their doctor when they experience symptoms. As a result of this aforementioned lack of awareness, people may come to hospitals when their disease has degenerated, or reached an advanced stage, resulting in lower possibilities of receiving effective treatment and curing their tumors. A case in point is in Indonesia, where approximately $70 \%$ of cancer patients visit a physician once their cancer is at a late stage, thus reducing their overall chance of survival (11).

Lack of awareness may not only worsen clinical outcome, but it can also be divisive in society and affect quality of life. As a hypothetical example, a young child with leukemia (in remission) may not be invited to attend a peer's birthday party as the hosts are scared to invite a leukemic patient, stemming from the stigma associated to condition, immunodeficiency, risk of bleeding, and in some cases, there can even be a misconception that the cancer itself is contagious.

Why is there a push to increase awareness surrounding leukemia, lymphoma, myeloma, and other hematological malignancies? The best opportunity for awareness campaigns is in changing attitudes and behaviors toward cancer prevention, screening, and early detection. Unfortunately, these strategies are very limited in leukemia, lymphoma, and myeloma, given the rapid and aggressive course of these diseases. However, awareness and education can initiate a cascade. Increased awareness and education lead to further support, which in turn allows for more research. And research leads to new and better treatments. With this aim, September was selected to be Blood Cancer Awareness Month each year, in order to raise funds for research and patient support organizations involved in hematological malignancies.

Unsurprisingly, a Google web search of 'cancer awareness month' is dominated by results related to "Pink October", which pertains to breast cancer awareness. Breast Cancer Awareness month, famously associated with the color pink, receives huge amounts of publicity, with numerous articles being published in popular media outlets rather than scientific journals. A PubMed search on 'cancer awareness months' identifies even fewer publications, and once again the results are predominantly related by breast cancer. Jacobsen and Jacobsen (12) investigated a potential relationship between the Breast Cancer Awareness Month initiative, and the number of subsequent breast cancer diagnoses in the following month, November, looking at years prior to, and following the introduction of the initiative (using SEER data to investigate such numbers). The authors demonstrated that between 1973 and 2005 there were some evident "spikes" in diagnoses in the month following Breast Cancer Awareness month, November (12). Two of these apparent increases in diagnoses could in fact be attributed to an overall increased awareness related to breast cancer diagnoses in females, as opposed to, for an example, and advance in diagnostic methods. In particular, there was a clear spike in November diagnoses in the mid-1990s, in the 3 years following the initial introduction of Breast Cancer Awareness Month. However, this increased trend did not continue in subsequent years (12). Breast cancer screening rates have significantly increased in the last 30 years, and the distribution of breast cancer diagnoses throughout the year has become more consistent and uniform, without any additional "November spikes". In brief, the introduction of a dedicated awareness month initiative was initially highly effective, and it is plausible that the importance of mammography was recognized thanks to the effect of a short-term awareness campaign, bringing further attention to breast cancer.

Awareness is extremely important also for patients who have endured and survived cancer, in particular the pediatric population, who are exposed to late effects of treatment. Such effects can have varied onset - months or even years after treatment, and are heterogenous in nature spanning from physical, cognitive, or psychological. A recent systematic literature review, with input from $>20$ different organizations, resulted in the creation of LEAP $^{3}$ AHEAD (Late Effects Awareness for Patients, Physicians and the Public; Advancing Health and Eliminating All Disparities), a multi-dimensional website centered on late effects (13). This is the first interactive, international website dedicated to acute lymphoblastic leukemia childhood cancer survivors and families, as well as physicians. It was developed with the aim to increase awareness about risks, detection, diagnosis, treatment, and prevention of medical and psychological late effects (13). Awareness and prevention are two sides of the same coin.

\section{PREVENTION}

Wikipedia defines prevention, referring to healthcare, as "preventive healthcare": measures to prevent diseases or injuries rather than curing them or treating their symptoms (14). Although great strides have been made to cure several types of cancer, cancer remains the second leading cause of death worldwide. Instead of waiting for state-of-the-art treatment breakthroughs, individuals can take action to protect themselves. Examples of such actions include participating in early screening, as well as following some general recommendations and tips to prevent cancer development. Such recommendations often form the basis of national initiatives aimed at curbing cancer rates. Early diagnosis is important; however, reducing the risk of getting cancer is even more important. Avoiding tobacco in all its forms, consuming a balanced diet, actively avoiding obesity, exercising regularly, consuming alcohol with moderation, and making quality sleep 
a priority, are easy and apparent ways to help prevent cancer, even if many people do not strictly follow them. Getting vaccinated, protecting our body from the sun, avoiding risky behavior such as unnecessary exposure to radiation or to industrial and environmental toxins are important things to keep in mind, especially in preventing hematologic neoplasms.

In order to stress the importance of our behavior in preventing cancer development, we appoint several examples. 1. The bone marrow is one of the most radiosensitive organs, and there is clear evidence that the risk of developing AML, acute lymphoblastic leukemia (ALL), and myelodysplastic syndromes (MDS) are higher after exposure to moderate-to-high doses ( $>0.5 \mathrm{~Sv}$ ) of ionizing radiation (15). Moreover, exceptionally high relative risks of deferred leukemia have been described following radiation exposure in childhood $(15,16)$. The majority of exposures, however, are typically at low doses as they result from natural background radiation, diagnostic medical tests, or occupational exposure. Accordingly, evaluating risks in the low dose range is critical for radiation-protection purposes, especially in children. Interestingly, recent data suggest that even exposure to low-dose radiation $<100 \mathrm{mSv}$, or even $<50 \mathrm{~Sv}$ during childhood, may be associated with increased risk of childhood ALL and subsequent MDS/AML (15, 16). This finding is particularly relevant as computerized tomography is a common source of low dose radiation. Nikkilä et al. demonstrated that cumulative red bone marrow dose from computed tomography (CT) scans showed an excess odds ratio of 0.13 (95\% confidence interval: 0.02 - 0.26) per $\mathrm{mGy}$. In other words, whilst CT may be a helpful diagnostic tool, it is on the other hand a source of low-dose radiation which can subsequently result in an increased risk of leukemia. 2. There is abundant evidence about the association between viral infection and lymphoma development. Epstein-Barr Virus infection is responsible for African Burkitt lymphoma, and increases the risk of both Hodgkin disease and follicular lymphoma $(17,18)$. Furthermore, Hepatitis B and C infections are similarly associated with an increased risk of non-Hodgkin lymphoma (19), with an additional risk increase in patients with concomitant HIV infection (20). Fabula docet: prevention is (at least) half of the cure, and the higher is the awareness, the better the prevention.

\section{EQUITY}

Equity can be a difficult concept to comprehend as the term itself has multiple definitions depending on the context, ranging from a financial setting, to in this case, the public health setting. Health equity, in its simplest form, means giving patients the care they

\section{REFERENCES}

1. American Cancer Society. Cancer Facts \& Figures 2020. Atlanta: American Cancer Society (2020).

2. O'Brien SG, Guilhot F, Larson RA, Gathmann I, Baccarani M, Cervantes F, et al. Imatinib Compared With Interferon and Low-Dose Cytarabine for need when they need it. The US Institute of Medicine indicates, health equity is "providing care that does not vary in quality because of personal characteristics such as gender, ethnicity, geographic location, and socioeconomic status" (21). Accordingly, and before looking at health equity in cancer, it is quite clear that awareness, prevention, and equity all go hand in hand. Higher rates of chronic and expensive illnesses, together with high rates of uninsured people among lower socioeconomic and minority populations, result in a greater reliance on emergency services, higher treatment costs, and, finally, a financial strain on providers and government programs. As an example, in rural parts of the USA, employer insurance coverage is lower than in comparable urban areas (22). Similarly, lower socioeconomic status among cancer patients has been seen in some cases to be associated with an elevated risk of suicide (23). We know that preventive medicine and early interventions are proven means to saving money and lives.

Returning back to cancer, the gains that have been made in the reduction of cancer incidence and mortality are unfortunately not shared by everyone. Disparities still exist with regards to ethnicity, gender, race, socioeconomic status, and geography (24). As an example, a review of global access to cancer medicines in 2020 showed a marked difference in the availability of cancer medicines between countries of varying income levels. Only 10\% of countries around the world listed all 25 cancer medications that appear on the World Health Organizations Model Lists of Essential Medicines. In contrast, on average, only 9 listed medicines were available in low-income nations (25).

In 2008, the National Institutes of Health Centers for Population Health and Health Disparities published a framework to elucidate the ecological determinants of disparities in cancer incidence, morbidity, and mortality (26). Interventions to eliminate disparities may be aimed at the multilevel factors, required to achieve improved cancer outcomes. Health systems are paying attention to disparities in the quality of their care and seeking remedies as healthcare costs rise, and consumers demand action.

In conclusion, awareness, prevention, and equity are still hot topics, even in 2021, as people still die of cancer in 2021, still due to a lack of awareness, prevention, equity. This is why it is so important that the 2021 World Cancer Day is dedicated to awareness, prevention and equity

\section{AUTHOR CONTRIBUTIONS}

Both authors equally contributed to the writing of this manuscript.

Newly Diagnosed Chronic-Phase Chronic Myeloid Leukemia. N Engl J Med (2003) 348:994-1004. doi: 10.1056/NEJMoa022457

3. Hochhaus A, Larson RA, Guilhot F, Radich JP, Branford S, Hughes TP, et al. Long-Term Outcomes of Imatinib Treatment for Chronic Myeloid Leukemia. N Engl J Med (2017) 376(10):917-27. doi: 10.1056/ NEJMoa1609324 
4. Caligaris Cappio F. Chronic Lymphocytic Leukemia: "Cinderella" is Becoming a Star. Mol Med (2009) 15(3-4):67-9. doi: 10.2119/molmed.2008.00126

5. Burger JA, Tedeschi A, Barr PM, Robak T, Owen C, Ghia P, et al. Ibrutinib as Initial Therapy for Patients With Chronic Lymphocytic Leukemia. N Engl J Med (2015) 373(25):2425-37. doi: 10.1056/NEJMoa1509388

6. Mateos MV, Warnecke RB, Oh A, Breen N, Gehlert S, Paskett E, et al. Management of Multiple Myeloma in the Newly Diagnosed Patient. Hematol Am Soc Hematol Educ Program (2017) 1):498-507. doi: 10.1182/asheducation-2017.1.498

7. Richard-Carpentier G, DiNardo CD. Single-Agent and Combination Biologics in Acute Myeloid Leukemia. Hematol Am Soc Hematol Educ Program (2019) 2019(1):548-56. doi: 10.1182/hematology.2019000059

8. Maude SL, Frey N, Shaw PA, Aplenc R, Barrett DM, Bunin NJ, et al. Chimeric Antigen Receptor T Cells for Sustained Remissions in Leukemia. N Engl J Med (2014) 371:1507-17. doi: 10.1056/NEJMoa1407222

9. Schuster SJ, Svoboda J, Chong EA, Nasta SD, Mato AR, ANak O, et al. Chimeric Antigen Receptor T Cells in Refractory B-Cell Lymphomas. N Engl J Med (2017) 377:2545-54. doi: 10.1056/NEJMoa1708566

10. Available at: https://en.wikipedia.org/wiki/Awareness.

11. Union for International Cancer Control. Uicc Special Reports (2010). Available at: http://old.uicc.org/index.php?option=com_content\&task=view\&id=16583.

12. Jacobsen GD, Jacobsen KH. Health Awareness Campaigns and Diagnosis Rates: Evidence From National Breast Cancer Awareness Month. J Health Econ (2011) 30(1):55-61. doi: 10.1016/j.jhealeco.2010.11.005

13. Klonoff-Cohen H, Navarro A, Klonoff EA. Late Effects Awareness Website for Pediatric Survivors of Acute Lymphocytic Leukemia. PloS One (2018) 13(2): e0193141. doi: 10.1371/journal.pone.0193141 eCollection 2018.

14. Available at: https://en.wikipedia.org/wiki/Prevention.

15. Little MP, Wakeford R, Borrego D, French B, Zablotska LB, Adams MJ, et al. Leukaemia and Myeloid Malignancy Among People Exposed to Low Doses ( $<100 \mathrm{mSv}$ ) of Ionising Radiation During Childhood: A Pooled Analysis of Nine Historical Cohort Studies. Lancet Haematol (2018) 5(8):e346-58. doi: 10.1016/S2352-3026(18)30092-9

16. Nikkilä A, Raitanen J, Lohi O, Auvinen A. Radiation Exposure From Computerized Tomography and Risk of Childhood Leukemia: Finnish Register-Based Case-Control Study of Childhood Leukemia (FRECCLE). Haematologica (2018) 103(11):1873-80. doi: 10.3324/haematol.2018.187716

17. Vockerodt M, Yap LF, Shannon-Lowe C, Curley H, Wei W, Vrzalikova K, et al. The Epstein-Barr Virus and the Pathogenesis of Lymphoma. J Pathol (2015) 235(2):312-22. doi: 10.1002/path.4459

18. Young LS, Yap LF, Murray PG. Epstein-Barr Virus: More Than 50 Years Old and Still Providing Surprises. Nat Rev Cancer (2016) 16:789-802. doi: 10.1038/nrc.2016.92

19. Marcucci F, Mele A. Hepatitis Viruses and non-Hodgkin Lymphoma: Epidemiology, Mechanisms of Tumorigenesis, and Therapeutic Opportunities. Blood (2011) 117(6):1792-8. doi: 10.1182/blood-2010-06-275818
20. Wang Q, De Luca A, Smith C, Zangerle R, Sambatakou H, Bonnet F, et al. Hepatitis Coinfection and Non Hodgkin Lymphoma Project Team for the Collaboration of Observational Hiv Epidemiological Research Europe (COHERE) in Eurocoord. Chronic Hepatitis B C Virus Infect Risk NonHodgkin Lymphoma HIV-Infect Patients: A Cohort Study Ann Intern Med (2017) 166(1):9-17. doi: 10.7326/M16-0240

21. Institute of Medicine (US) Committee on Quality of Health Care in America. Improving the 21st-century Health Care System. In: Crossing the Quality Chasm: A New Health System for the 21st Century, vol. 2. Washington (DC: National Academies Press (US (2001). Available at: https://www.ncbi.nlm.nih. gov/books/NBK222265/.

22. Charlton M, Schlichting J, Chioreso C, Ward M, Vikas P. Challenges of Rural Cancer Care in the United States. Oncol (Williston Park) (2015) 29(9):633-40.

23. Clougherty J, Souza K, Cullen, M. Work and its Role in Shaping the Social Gradient in Health. Ann New York Acad Sci (2010) 1186(1):102-24. doi: 10.1111/j.1749-6632.2009.05338.x

24. Weinberg AD, Jackson PM, DeCourtney CA, Cravatt K, Ogo J, Sanchez MM, et al. Progress in Addressing Disparities Through Comprehensive Cancer Control. Cancer Causes Control (2010) 21:2015-21. doi: 10.1007/s10552-0109649-8

25. Cortes J, Perez-García J, Llombart-Cussac A, Curigliano G, El Saghir N, Cardoso F, et al. Enhancing Global Access to Cancer Medicines. CA: A Cancer J Clin (2020) 70(2):105-24. doi: 10.3322/caac.21597

26. Warnecke RB, Oh A, Breen N, Gehlert S, Paskett E, Tucker KL, et al. Approaching Health Disparities From a Population Perspective: The National Institutes of Health Centers for Population Health and Health Disparities. Am J Public Health (2008) 98:1608-15. doi: 10.2105/ AJPH.2006.102525

Disclaimer: Dominic Kaye is an employee of the Frontiers in Oncology Editorial Office.

Conflict of Interest: Since [2018], the co-author [DK] has been employed by Frontiers Media SA. [DK] declared his/her affiliation with Frontiers, and the handling Editor states that the process nevertheless met the standards of a fair and objective review.

Copyright $\odot 2021$ Kaye and Isidori. This is an open-access article distributed under the terms of the Creative Commons Attribution License (CC BY). The use, distribution or reproduction in other forums is permitted, provided the original author(s) and the copyright owner(s) are credited and that the original publication in this journal is cited, in accordance with accepted academic practice. No use, distribution or reproduction is permitted which does not comply with these terms. 